\title{
In-Situ Measurement of Forrest Soil Gases using Quadrupole Mass Spectrometry
}

Timothy L. Porter ${ }^{*}$ and T. Randall Dillingham ${ }^{2}$
${ }^{1}$ University of Nevada Las Vegas, Department of Physics and Astronomy, Las Vegas, NV, 89154, USA
${ }^{2}$ Northern Arizona University, Department of Physics and Astronomy, Flagstaff, AZ, 86001, USA

\section{Abstract}

The net effect of forest soils on the overall atmospheric concentration of methane and carbon dioxide is complex and relies upon many different factors. The flux of these gases from the soils may vary significantly depending upon temperature, water content, soil compaction, soil composition, root structure within the soil, decaying forest components within the soil, and other factors. We have developed and tested a portable, battery powered quadrupole mass spectrometer that allows for in-situ, real time measurement of the concentration of gases in soils. This instrument allows for rapid, simultaneous quantification of methane, carbon dioxide, water vapor and other gases in the near surface region of the soils. Here, we have measured the concentrations of methane and carbon dioxide in the soils of the Coconino National Forest, comparing gas levels in regions of the forest that have been mechanically thinned vs. nearby regions that have been undisturbed.

\section{Introduction}

Methane is a potent greenhouse gas with an effect on greenhouse warming approximately 30 times greater than that of carbon dioxide per unit of gas. Human induced sources of atmospheric methane such as fossil fuel production, storage, transportation, and livestock farming now constitute the majority of methane emissions worldwide [1]. Naturally occurring sources also contribute a large fraction of the methane measured in the atmosphere. The largest source of naturally occurring methane is the worldwide wetlands [2]. Other natural methane sources include thawing tundra and terrestrial plant life [3]. Soils in various ecosystems may, under certain conditions, act as either methane sinks or as sources of atmospheric methane. In forest soils, aerobic conditions that are found in highly aerated zones may house methane consuming microorganisms that lead to an overall methane sink effect [4]. Anaerobic conditions may also be found within forest soils. Here, net oxygen depletion may lead to enhanced production of methane by soil bacteria [5]. Other studies have also shown that soils are capable of becoming net sources of methane under certain conditions [6-8]. The overall balance of water in forest soils may also be a factor in the methane cycle observed in these systems [9].

Forest soils also play a role in the overall carbon dioxide concentration of our atmosphere. Components of the soil in forests that produce carbon dioxide include microorganisms, root systems, and plant fauna [10-12]. The production of carbon dioxide by these systems is generally referred to as soil respiration. Studies have shown that up to $70 \%$ of total forest ecosystem carbon dioxide respiration in temperate forests originates from the soil [13-15]. Overall, the net effect of forest soils on the atmospheric concentration of carbon dioxide (and methane to a similar extent) is complex and relies upon many different factors. The overall flux of carbon dioxide may vary significantly depending upon temperature $[16,17]$, water content $[18,19]$, soil compaction, soil composition, root structure within the soil [20,21], decaying forest components within the soil [22], and other factors. Many of these factors vary seasonally, and can change significantly over periods of years and even decades.

We have developed and tested a portable, battery powered quadrupole mass spectrometer that allows for in-situ, real time measurement of the concentration of gases in various soils. This instrument allows for rapid, simultaneous quantification of methane, carbon dioxide, water vapor and other gases in the near surface region of the soils. Here, we have measured the concentrations of methane and carbon dioxide in the soils of the Coconino National Forest, comparing gas levels in regions of the forest that have been mechanically thinned or logged vs. nearby regions that have been undisturbed.

\section{Materials and Method}

Figure 1 shows a photo and major components of the portable mass spectrometer instrument. The instrument we have used in this study is based upon a Micropole quadrupole mass spectrometer from Horiba, Inc. The basic design has been described in a previous communication by us [23]. The Micropole unit we are using can analyze masses in the range of 0-300 AMU, and can measure partial pressures down to 1010 Torr. The quadrupole analyzer itself measures approximately 3.5 $\mathrm{cm}$ in length, and is mounted on a standard high vacuum mini conflat flange. Power for the system is provided by a Li-Ion 24 -Volt battery pack. The battery is rated at 5 Amp hours, with the charging unit built into the portable mass-spec unit. The battery pack feeds into a $24 \mathrm{~V}$ DC-DC converter rated at $200 \mathrm{~W}$, which is used to keep the voltages supplied to the pumps and the quadrupole analyzer constant at $24 \mathrm{~V}$. The vacuum system supporting the mass spectrometer consists of a Pfeiffer 41/min diaphragm pump for obtaining rough vacuum in the gas inlet system and simultaneously backing the turbo pump, and a Pfeiffer $10 \mathrm{l} / \mathrm{s}$ turbomolecular pump for obtaining high vacuum in the quadrupole analysis section of the instrument. A vacuum gauge provides data on system pressure outside of the analysis chamber, which contains its own integrated total pressure monitor [24].

The differentially pumped sample gas inlet system we have built has been modified somewhat from previous applications on vapors from liquid samples. This sampling system is designed to directly measure ambient gas concentrations from soils. Initially, gas samples

${ }^{\overline{ }}$ Corresponding Author: Prof. Timothy L. Porter, University of Nevada Las Vegas, Department of Physics and Astronomy, Las Vegas, NV 89154, USA; E-mail: tim.porter@unlv.edu

Citation: Porter TL, Dillingham TR (2018) In-Situ Measurement of Forrest Soi Gases using Quadrupole Mass Spectrometry. Int J Earth Environ Sci 3: 149. doi: https://doi.org/10.15344/2456-351X/2018/149

Copyright: (c) 2018 Porter, et al. This is an open-access article distributed under the terms of the Creative Commons Attribution License, which permits unrestricted use, distribution, and reproduction in any medium, provided the original author and source are credited. 
Citation: Porter TL, Dillingham TR (2018) In-Situ Measurement of Forrest Soil Gases using Quadrupole Mass Spectrometry. Int J Earth Environ Sci 3: 149. doi: https://doi.org/10.15344/2456-351X/2018/149

Page 2 of 6

at ambient pressure pass through a $20 \mu \mathrm{m}$ orifice, laser drilled into a mini-conflat flange, into a region rough-pumped by the diaphragm pump. This inlet stage has been built to minimize the intake of gases into the analysis system other than gases directly outside of the first differential pumping orifice. A second orifice of diameter $10 \mu \mathrm{m}$, isolates this rough pumped region from the high-vacuum, turbopumped analysis chamber. This system of differential pumping allows samples to be inlet from ambient air, and quickly enter the high-vacuum analysis region of the system. When operating, the pressure in the analysis chamber is approximately $5 \times 10^{-6}$ Torr after about $5 \mathrm{~min}$. of turbo pump operation. After approximately 15 minutes of operation, the analysis chamber pressure is reduced to approximately $1-2 \times 10^{-6}$ Torr. This ultimate pressure is essentially pinned at this value, determined by the inlet gas load through the two inlet orifices. During measurements, the quadrupole also provides total pressure readings in the analysis chamber.

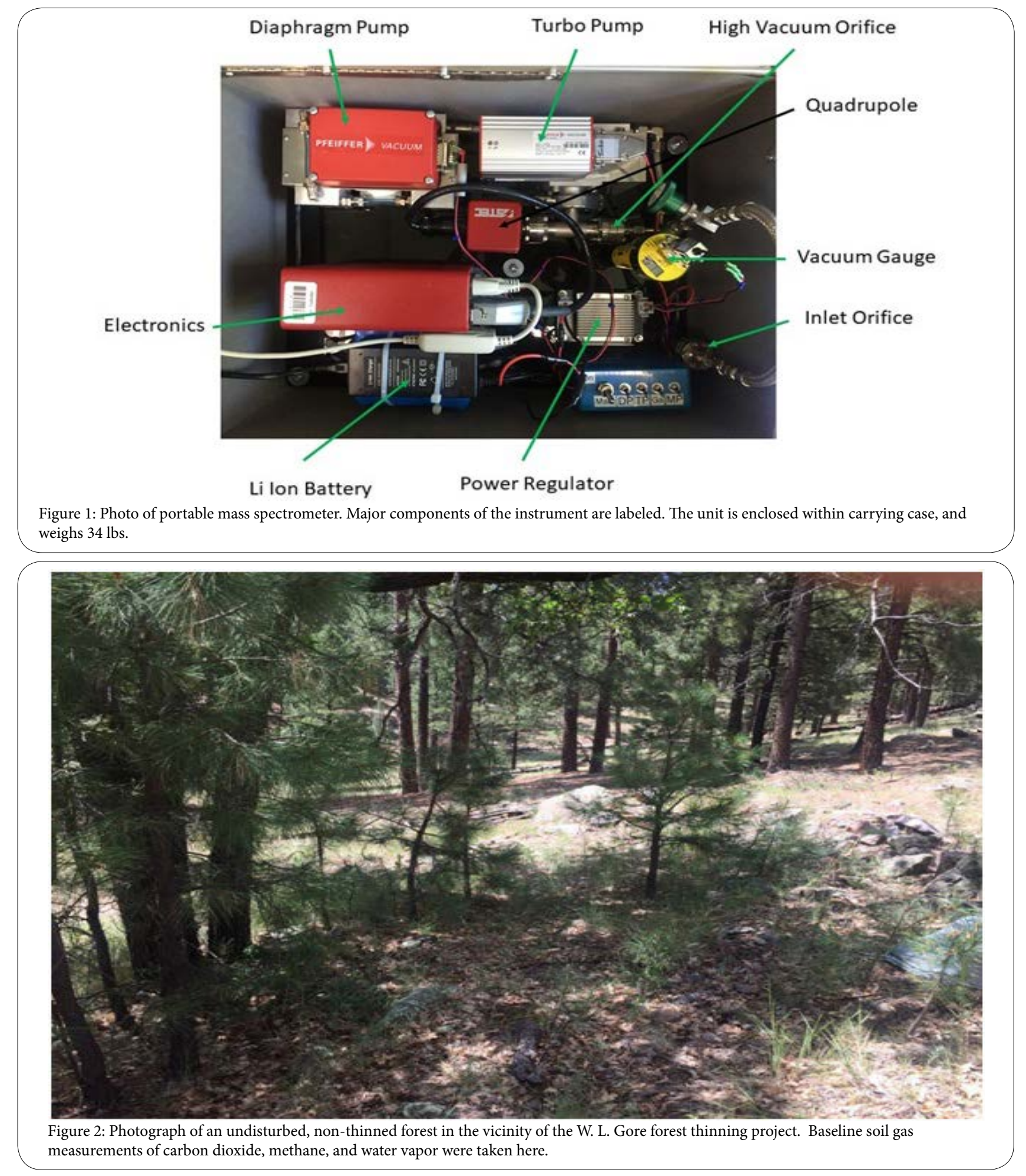


Citation: Porter TL, Dillingham TR (2018) In-Situ Measurement of Forrest Soil Gases using Quadrupole Mass Spectrometry. Int J Earth Environ Sci 3: 149. doi: https://doi.org/10.15344/2456-351X/2018/149

Page 3 of 6

Measurements taken in both the W. L. Gore and Howard forest areas were monitored for rainfall prior to field readings. In both cases, the areas under study received a minimum of 10 or 11 consecutive days of measurable rain prior to readings. Total rainfall in the days prior to measurement varied somewhat owing to the monsoon activity producing the precipitation, but water vapor concentrations in the soils measured provide a basis for comparison of readings.

\section{Results and Discussion}

Figure 2 shows a photograph of an undisturbed, non-thinned forest in the vicinity of the W. L. Gore forest thinning project. We see in this figure that forest growth is dense and varied. On the ground, there is a layer ranging from 3-4 inches thick of pine needles, tree and bush leaves, bark chips, pine cones, and other types of forest debris.

The thinning of forests is performed for many reasons. These include commercial thinning or logging, thinning of overgrown forests to restore their overall health, and thinning for the direct purpose of reducing wildfire potential [25]. The thinning of forests may directly affect the net flux of carbon dioxide and methane from the soils over many years, owing to the reduction of root systems within the soils $[26,27]$, and to the reduction of biomass and its subsequent effect on soil microbes [28] over time. The thinning of the forests will also have an effect on the forest canopies and forest production, which may both directly and indirectly change the average moisture content of the soils over long periods of time [29].

The mechanical thinning of areas within the Coconino National Forest to reduce the potential of damaging wildfires has been performed in many areas near Flagstaff, AZ. In 2012, a \$10M bond was approved to support the Flagstaff Watershed Protection Project. This project was specifically designed to mechanically thin forest areas in the Rio de Flag and Lake Mary watersheds to reduce wildfire probability. Treatment of forest areas within the project area are expected to continue for 8-10 years. Much of the treatment focuses on the removal of excess trees that are of small diameter, typically 10 inches or less. The types of trees that are contained within these areas include ponderosa pine, pinion pine, limber pine, aspen, Gambel oak, Douglas fir, white fir, sub-alpine fir, cork bark fir, Engelmann spruce, blue spruce, alligator juniper, rocky mountain juniper and Utah juniper. Most areas contain a majority of ponderosa pine. In addition to tree removal, other low-lying brush and debris may be collected or removed. Some prescribed burning of piles of collected debris may occur in certain areas as well. Here, we have measured the methane, carbon dioxide, and water vapor content of mechanically thinned vs. non-thinned forest soils in the W. L. Gore thinning component of the Flagstaff Watershed Restoration Project.

Other areas in the Coconino National Forest may be thinned or logged in a more traditional manner. Typically, in areas that are commercially logged, trees of both large and medium diameter may be removed along with other components of the forest. Many of these logging/thinning projects in Northern Arizona are part of the Four Forests Restoration Initiative. Goals of the Four Forest Restoration Initiative are to restore the structure, pattern, composition, and health of fire-adapted ponderosa pine ecosystems; reduce fuels and the risk of unnaturally severe wildfires; and provide for wildlife and plant diversity. As part of this study, we measured methane, carbon dioxide and water vapor concentrations in the "Howard" project just south of Flagstaff where logging began in 2015. Areas very close to the Howard project that have been undisturbed were also studied to use for comparison.

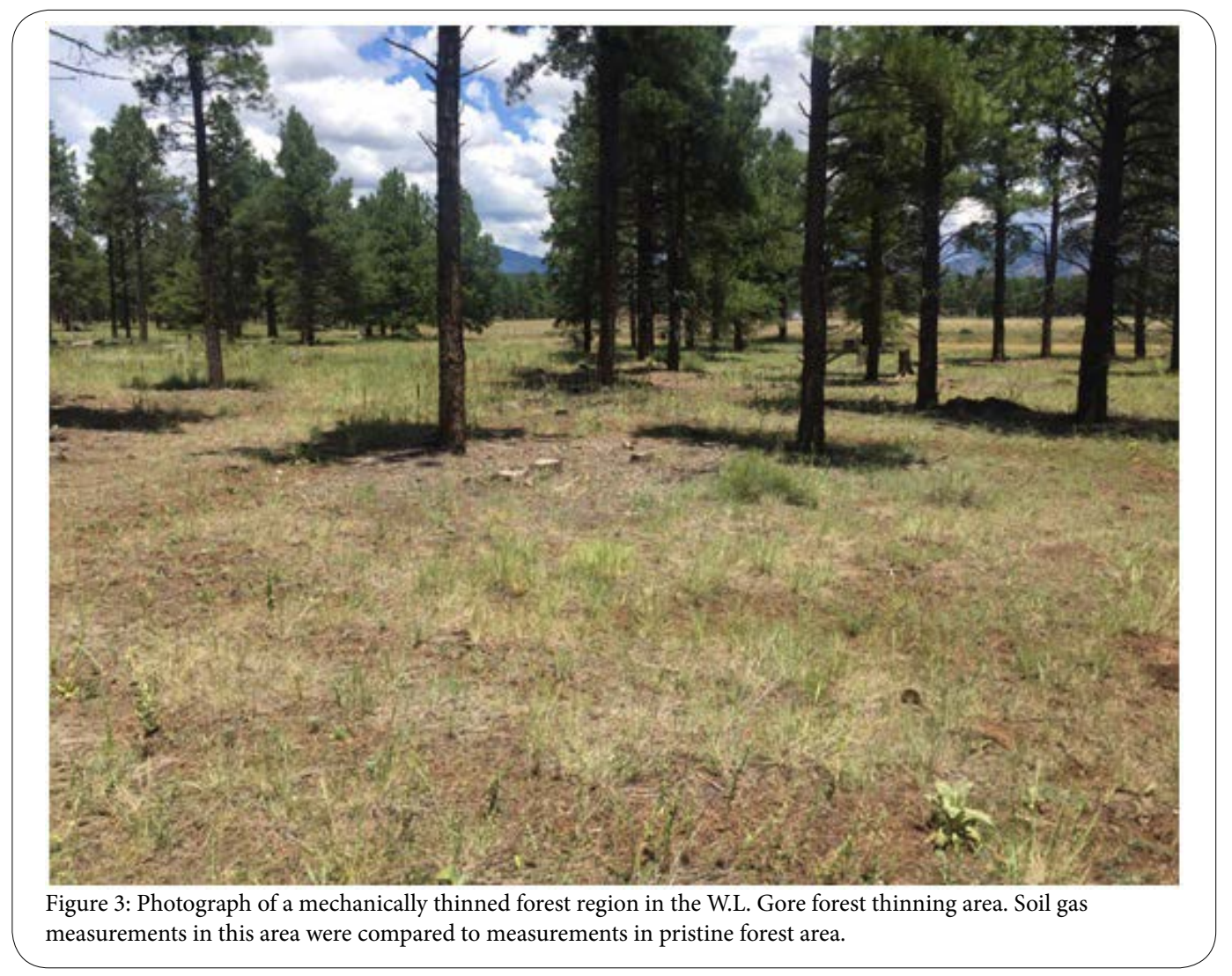


Near ground level in a pristine, non-thinned forest we measure a carbon dioxide partial pressure of $2.75 \times 10^{-8}$ Torr in ambient air with our mass spectrometer. If we assume an ambient, humidity corrected carbon dioxide concentration of $375 \mu \mathrm{mol} / \mathrm{mol}$, or $\mathrm{ppm}$, we can use this value as a comparison for further measurements in the soil. This concentration is within reasonable limits for generally accepted values, though we note that ground based carbon dioxide concentrations may vary over a wide range, even over the course of a single day. Gas concentration values we calculate this way, however, will only be approximate in the absence of exact ambient $\mathrm{CO}_{2}$ concentrations and calibration standards for this particular instrument. Partial pressure measurements from an electron-impact quadrupole mass spectrometer rarely are true partial pressures. Instead, they measure peak detector electron currents at the various masses. Factors such as electron impact ionization probabilities for different gas molecules, molecular fragmentation fractions, and other factors would need to be calculated for each mass detected. Here, we will instead rely primarily on comparisons of relative soil gas concentrations with readings taken in the atmosphere in the same region.

Figure 3 shows a photograph of a mechanically thinned forest region in the W.L. Gore forest thinning area. This area is part of the Flagstaff Watershed Protection Project forest thinning project in the regions surrounding Flagstaff, AZ. This area of the forest has had many smaller trees removed, as well as non pine trees, bushes, ground lying wood, pine cones and other debris. Thinning in this area was completed in the fall of 2015. Ground cover in this area is generally sparse when compared to the untouched, or pristine forest area. Here, the soil is generally covered by less than one inch of pine needles, and little else. Some grass and weeds are present on the surface, and are assumed to contribute to some level of forest soil decomposition of organic matter.

All soil readings were performed in the same manner. A small diameter hole, approximately $3 / 8 \mathrm{inch}$, was punched into the soil. The inlet probe to the mass spectrometer was inserted 1 inch into the hole, with a snug fit around the cylindrical input probe. The ground level was sealed with pressure from a 1.33-inch diameter steel flange. The resulting setup was then covered with soil to further seal the inlet area from any outside air. Once the inlet probe was sealed in place, the pumping system was started, and tiny amounts of air within the soil-probe area began to be drawn into the system. The system was allowed to come to vacuum equilibrium for 10 minutes, after which the quadrupole analyzer was switched on and readings were taken. Looking at Table 1, we see measured relative concentrations of carbon dioxide, methane and water vapor from both the pristine forest area and the mechanically thinned area approximately 300 yards away. For carbon dioxide, the concentration in the pristine forest soil measures 2.96 times the value in the above ground atmosphere, and in the mechanically thinned forest area 2.66 times higher. For methane concentrations, both measured values are lower than above ground readings, with the relative concentrations being 0.56 and 0.42 respectively. For both sets of readings, the water vapor concentration was essentially constant, about 1.5 times the water vapor level in the above ground air.

Relative carbon dioxide levels such as these from air samples are generally straightforward, as in an instrument such as the one we have used in this study there are few additional masses (at 44 AMU) to interfere with the measured $\mathrm{CO}_{2}$ current peak. The measurement of methane is less straightforward, however. In an electron-impact quadrupole mass spectrometer, the standard mass spectrum for methane consists of a major peak at mass 16 , and secondary peaks at mass 15 and mass 14 . The primary components of these peaks are $\mathrm{CH}_{4}$ at mass $16, \mathrm{CH}_{3}$ at mass 15 and $\mathrm{CH}_{2}$ at mass 14 . In the latter two, the electron-impact ionization process has stripped off one or two hydrogen atoms from the intact methane molecule. These peaks will also typically contain some percentage of other gas fragments and a small percentage of doubly charged oxygen at mass 16 . A standard methane spectrum from air will have the primary peak at mass 16 , with the secondary mass 15 peak at $80 \%$ peak height and the mass 14 peak at approximately at $20 \%$ of the maximum mass 16 peak height. Here, our methane spectra displayed the standard methane spectrum appearance in all cases. As with carbon dioxide, we have relied on relative methane measurements between the soils sampled rather than approximate absolute values. Also, we note that these soil measurements are not directly giving data on the net flux of these gases into or out of the forest soils. We are measuring the real-time, in-situ concentrations of methane, carbon dioxide and water vapor directly within the soil itself. These measured levels may play a potentially significant role in the ultimate gas flux into the atmosphere, however.

Figure 4 shows a photograph of the forest area south of Flagstaff that has been thinned or logged. In this area, much more of the forest plant and tree life has been removed when compared to the areas within the Flagstaff Watershed Protection Project. This area has been commercially logged, and is referred to as the Howard project. Here, both large and small diameter trees have been removed, along with much of the other forest plant and tree life. Some trees remain, however. The soil is approximately $50 \%$ bare, and little growth of grass or weeds has occurred. The logging of this area was completed in the spring of 2017.

In Table 2 shows that, we indicate the concentrations of carbon dioxide, methane, and water vapor from the Howard forest area. This is an area that has been commercially logged within 6 months prior to this data being taken.

Here, the level of carbon dioxide in the logged forest soil is smaller than that found in either pristine or more lightly thinned forest soils. Carbon dioxide is $20 \%$ lower than in the pristine forest soil and $17 \%$ lower than the mechanically thinned forest soil. In the case of methane, the measured concentration in this soil was substantially higher than that found in the earlier soils. The measured concentration is over 5 times that in above ground air, and almost 9 times greater than that found in the pristine forest soil. The water vapor concentration in this soil was consistent with the other soils tested.

\begin{tabular}{|c|c|c|c|}
\hline & Carbon Dioxide & Methane & 0.56 \\
\hline Pristine Forest Soil & 2.96 & 0.42 & 1.44 \\
\hline \multicolumn{2}{|c|}{ Thinned Forest Soil } & 2.66 & 1.41 \\
\hline
\end{tabular}
Table 1: Factor differences from air baselines (baselines $=1.0$ ) for pristine and thinned forest soils. Air samples and pristine soil measurements
level is 0.9 that of the pristine forest soil, and methane is 0.75.




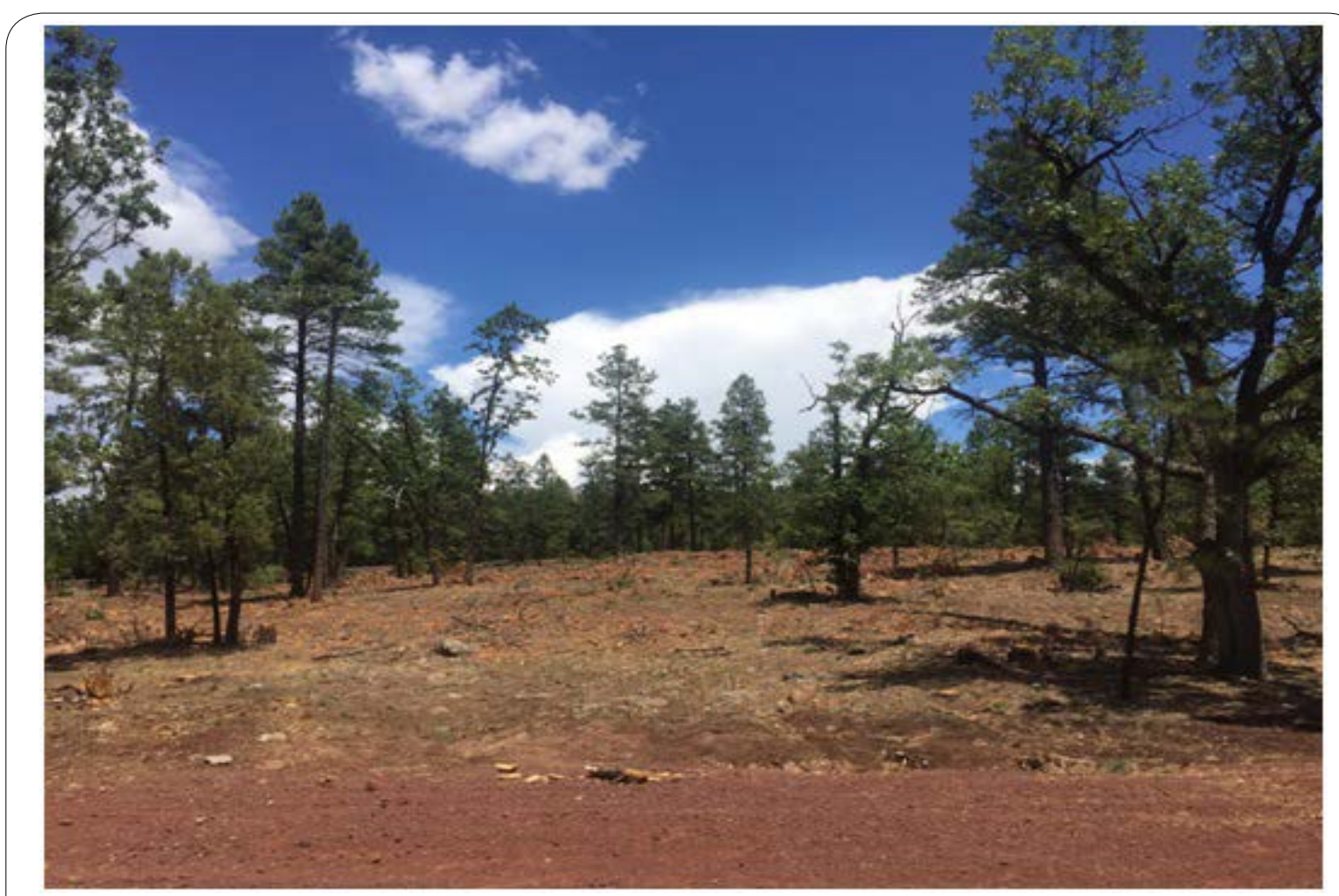

Figure 4: Photograph of the Howard forest area south of Flagstaff that has been thinned and logged.

\begin{tabular}{|c|c|c|c|}
\hline & Carbon Dioxide & Methane & Water Vapor \\
\hline Pristine Forest Soil & 2.76 & 0.63 & 1.40 \\
\hline Logged Forest Soil & 2.22 & 5.1 & 1.37 \\
\hline
\end{tabular}

Table 2: Factor differences from air baselines for pristine and logged forest soils. Air samples and pristine soil measurements were taken from a forest area approximately 200 yards from the mechanically logged forest region. In the logged forest, the carbon dioxide soil level is 0.75 that of the nearby pristine forest soil, and methane is 9.0 .

For carbon dioxide, components of the soil that contribute to respiration include microorganisms, root systems, and plant fauna [10-12]. Here, we have measured $\mathrm{CO}_{2}$ levels that are greater than atmospheric levels by over a factor of two in all three of the areas that we have sampled. The soil concentrations of $\mathrm{CO}_{2}$ decrease somewhat as we transition from pristine forest to thinned forest to logged forest, however. With the soil water vapor levels in the soils nearly constant, seasonal attributes constant, and time of day and ambient temperature nearly the same for all areas, the variations in carbon dioxide concentrations may be due primarily to differences in soil microorganisms, plant fauna and root systems. Here, we expect that the presence of all three of these contributing factors within the soils decreases as the forests are increasingly thinned. Soil carbon dioxide measurements in these same locations in future years may yield additional insights regarding respiration as the forests regrow after these types of thinning procedures.

In the case of methane concentration, the soil level measured in the lightly thinned forest area was found to be lower than in the pristine forest soil by $25 \%$, and both lower than atmospheric, above ground methane concentrations by an approximate factor of two. In soils, net $\mathrm{CH}_{4}$ flux is the result of two processes acting against one another. Methane is consumed through oxidation by soil microbes under conditions where oxygen is abundant, such as lightly packed soils that are damp enough to support microbial growth but not so dense or wet as to inhibit the diffusion of oxygen through the soil. In this case, the soil may act as an overall methane sink. Under conditions where oxygen is not present in the soils, the opposite may happen and methane is ultimately produced. Here, it may be safe to assume that under nearly identical soil and soil humidity conditions, the lightly thinned forest soil may simply contain somewhat fewer microbes producing methane and/or slightly elevated aerobic methane oxidation activity. In the heavily thinned or logged area (Howard) we measured a very high level of soil methane. While the soil water vapor level was similar to the previous forest areas studied, the soil conditions were visibly different. The forest had been recently logged, and the top soil regions were more compacted than normal. Visible amounts of sawdust were present on and near the soil surface. The soil was also more exposed to the sunlight owing to the removal of more trees. It is possible that these conditions led to a significant, local spike in methane production. Over time, this enhanced methane production may be reduced greatly, and future soil gas concentration measurements in this area will be performed by us over the next several years.

\section{Conclusion}

We have fabricated a portable, battery-powered quadrupole mass spectrometer for use in in-situ, real-time measurement of carbon dioxide, methane, and water vapor concentrations in forest 
Citation: Porter TL, Dillingham TR (2018) In-Situ Measurement of Forrest Soil Gases using Quadrupole Mass Spectrometry. Int J Earth Environ Sci 3: 149. doi: https://doi.org/10.15344/2456-351X/2018/149

Page 6 of 6

soils. Initial measurements of these gases show variations in gas concentrations in forest soils in regions that have been thinned or logged when compared to pristine forests. More comprehensive studies in these areas, sampling greater numbers of soil areas over seasonal and yearly time periods will be required to more exactly quantify the relationships between these soil gases and the forest conditions themselves. Further development of our instrumentation may also include soil gas inlet systems that differentiate soil gas concentrations as a function of depth in the soils.

\section{Competing Interests}

The authors declare that no competing interests exist.

\section{References}

1. Bousquet $P$, Ciais $P$, Miller JB, Dlugokencky EJ, Hauglustaine DA, et al (2006) Contribution of Anthropogenic and Natural Sources to Atmospheric Methane Variability. Nature 443: 439-443.

2. Wuebbles DJ, Hayhoe K (2002) Atmospheric Methane and Global Change Earth Science Reviews 57: 177-210.

3. Keppler F, Hamilton JT, Brass M, Röckmann T (2006) Methane Emissions from Terrestrial Plants Under Aerobic Conditions. Nature 439: 187-191.

4. Hanson RS (1980) Ecology and Diversity of Methylotrophic Organisms Adv Appl Microbiology 26: 3-39.

5. Sexstone AJ, Mains CN (1989) Production of Methane and Ethylene in Organic Horizons of Spruce Forest Soils. Soil Biology and Biochemistry 22: $135-139$

6. Andersen BL, Bidoglio G, Leip A, Rembges D (1998) A New Method to Study Simultaneous Methane Oxidation and Methane Production in Soils. Global Biogeochem. Cycles 12: 587-594.

7. Yavitt JB, Fahey TJSimmons JA (1995) Methane and Carbon Dioxide Dynamics in a Northern Hardwood Ecosystem. Soil Sci Soc Am J 59: 796804.

8. Chan AS, Parkin TB (2001) Methane Oxidation and Production Activity in Soils From Natural and Agricultural Systems. J Environ Qual 30: 18961903.

9. Shoemaker JK, Keenan TF, Hollinger DY, Richardson AD (2014) Forest Ecosystem Changes from Annual Methane Source to Sink Depending on Late Summer Water Balance. Geophysical Research Letters 41: 673-679.

10. Boone RD, Nadelhoffer KJ, Canary JD, Kaye JP (1998) Roots Exert a Strong Influence on the Temperature Sensitivity of Soil Respiration. Nature 396: 570-572.

11. Buchmann N (2000) Biotic and Abiotic Factors Controlling Soil Respiration in Picea Abies Stands. Soil Biology and Biochemistry 32: 1625-1635.

12. Dixon RK, Solomon AM, Brown S, Houghton RA, Trexier MC, et al. (1994) Carbon Pools and Carbon Flux of Forest Ecosystems. Science 263: 185190

13. Gouklen ML, Munger JW, Fan SM, Daube BC, Wofsy SC, et al. (1996) Measurements of Carbon Sequestration by Long Term Eddy Covariance Methods in a CRitical Evaluation of Accuracy. Global Change Biol 2: 169182

14. Law BE, Ryan MG, Anthoni PM (1999) Seasonal and Annual Respiration in a Ponderosa Pine Ecosystem. Global Change Biol 5: 169-182.

15. Davidson EA, Janssens LA (2006) Temperature Sensitivity of Soil Carbon Decomposition and Feedbacks to Climate Change. Nature 440: 165-173.

16. Parkin TB, Kaspar TC (2003) Temperature Controls on Diurnal Carbon Dioxide Flux. Soil Science Society of America Journal 67: 1763-1772.

17. Londo AJ, Messina MG, Schoenholtz SH (1999) Forest Harvesting Effects on Soil Temperature, Moisture, and Respiration in a Bottomland Hardwood Forest. Soil Society of America Journal 63: 637-644.

18. Tang J, Qi Y, Xu M, Misson L, Goldstein AH, et al. (2005) Forest Thinning and Soil Respiration in a Ponderosa Pine Plantation in the Sierra Nevada. Tree Physiology 25: 57-66.

19. Xu M, Qi Y (2001) Soil Surface CO2 Efflux and its Spatial and Temporal Variations in a Young Ponderosa Pine Plantation in Northern California. Global Change Biol 7: 667-677.
20. Hanson PJ, Edwards NT, Garten CT, Andrews JA (2000) Separating Root and Soil Microbial Contributions to Soil Respiration: A Review of Methods and Observations. Biogeochemistry 48: 115-146.

21. Högberg P, Nordgren A, Buchmann N, Taylor AF, Ekblad A, et al. (2001) Large Scale Forest Girdling Shows That Current Photosynthesis Drives Sopil Respiration. Nature 411: 789-792.

22. Billings SA, Richter DD, Yarie J (1998) Soil Carbon Dioxide Fluxes and Profile Concentrations in Two Boreal Forests. Canadian Journal of Forest Research 28: 1773-1783.

23. Porter TL, Dillingham TR, Cornelison DM, Venedam RJ, Williams G, et al. (2009) Design of a Portable, Battery Powered Quadruple Mass Spectrometer System for Real-Time Sampling of Materials. Proc Mat Res Soc 1169: 29-34

24. Tripathi D, Jiang Y-L, Kumar D (2010) SABP2, a Methyl Salicylate Esterase is required for the Systemic Acquired Resistance Induced by AcibenzolarS-Methyl in Plants. FEBS Letters 584: 3458-3463.

25. Covington W, Fule PZ, Moore MM, Hart SC, Kolb TE, et al. (1997) Restoring Ecosystem Health in Ponderosa Pine Forests of the Southwest. Journal of Forestry 95: 23-29.

26. Tian DL, Peng YY, Yan WD, et al. (2010) Effects of Thinning and Litter Fall Removal on Fine Root Production and Soil Organic Carbon Content in Masson Line Plantations. Pedosphere 20: 486-493.

27. Olajuyigbe S, Tobin B, Saunders M, Nieuwenhuis M (2012) Forest Thinning and Soil Respiration in a Sitka Spruce Forest in Ireland. Agricultural and Forest Meteorology 157: 86-95.

28. Ma S, Chen J, North M, Erickson HE, Bresee M, et al. (2004) Short Term Effects of Experimental Burning and Thinning on Soil Respiration in an Old Growth Mixed Conifer Forest. Environmental Management. 33: 5148-5159.

29. Gray AN, Spikes TA, Easter MJ (2002) Microclimatic and Soil Moisture Responses to Gap Formation in Coastal Douglas Fir Forests. Can J For Res 32: 332-343. 